\title{
Teatro com os bebês: Espaço de enunciações, afigurações e brincadeiras
}

\author{
Theater with babies: \\ Space of enuncia, afigurações and jokes
}

Teatro con bebés: Espacio de enunciación, afigurações y bromas

Luiz Pereira'

https://orcid.org/0000-000I-6666-1627

Jader Janer Moreira Lopes²

https://orcid.org/0000-0003-35 I0-8647

\begin{abstract}
Resumo: Este artigo contribui para algumas reflexões do campo de Estudos da Infância, em consonância com a metodologia de pesquisa com bebês a partir da oferta de uma atividade estética que nomeamos Teatro Com Bebês. As enunciações dos bebês na relação com a oferta de um teatro, sim, teatro! Usamos várias referências conceituais presentes no teatro infantil e adulto para elaboração da atividade, cenário, figurino, adereços e proposta de narrativa. O diferencial do trabalho proposto é a aposta que a plateia e os atores são os mesmos, ou seja, o que nos interessou foram a teatralidade do humano e as enunciações surgidas durante a oferta da atividade. Sinalizamos a importância da organização de um meio socialmente produzido, gerador de vivências, situações estéticas, brincantes e constituidoras de novidades. É a possibilidade da reinvenção do teatro a partir dos bebês e com eles.
\end{abstract}

Palavras-chave: Pesquisa com bebês. Teatro com bebês. Estudos da Infância.

Abstract: This article contributes to some reflections in the field of childhood studies, in line with the research methodology with babies from the offer of an aesthetic activity that we call Theater With Babies. Babies' enunciation in relation to the offer of a theater, yes theater! We used several conceptual references present in the children's and adult theater to elaborate the activity, scenery, costumes, props and narrative proposal. The differential of the proposed work is the bet that the audience and the actors are the same, that is, what interested us were the theatricality of the human and the enunciations that arose during the offer of the activity. We signal

\footnotetext{
' Doutor em Educação pela Universidade Federal Fluminense (UFF). Professor substituto do ensino superior da Fundação de Apoio à Escola Técnica em Três Rios-RJ. E-mail: luizmiguelp@gmail.com

${ }^{2}$ Doutor em Educação pela Universidade Federal Fluminense (UFF). Professor do programa de pós-graduação da Universidade Federal de Juiz de Fora e da Universidade Federal Fluminense. Coordenador do Grupo de Pesquisa e Estudos em Geografia da Infância - GRUPEGI. E-mail: jjanergeo@gmail.com
}

Olhar de professor, Ponta Grossa, v. 24, p. I-24, e-17609.021, 2021.

Disponível em <https://revistas2.uepg.br/index.php/olhardeprofessor> 
the importance of organizing a socially produced environment, which generates experiences, aesthetic, playful situations and constitutes news. It is the possibility of reinventing the theater from the babies and with them.

Keywords: Research with babies. Theater with babies. Childhood studies.

Resumen: Este artículo contribuye con algunas reflexiones en el campo de los estudios de la infancia, en línea con la metodología de investigación con bebés basada en la oferta de una actividad estética que llamamos Teatro Com Bebês. Declaraciones de bebés en relación a la oferta del teatro, ¡sí teatro! Utilizamos varios referentes conceptuales presentes en el teatro infantil y de adultos para elaborar la actividad, escenografía, vestuario, accesorios y propuesta narrativa. El diferencial de la obra es una apuesta en la que el público y los actores sean los mismo, es decir, lo que nos interesó fue la teatralidad de lo humano y las enunciaciones que surgieron durante la realización de la actividad. Señalamos la importancia de organizar un medio de producción social, que genera vivencias, situaciones estéticas y lúdica que constituye novedades. Es la posibilidad de reinventar el teatro desde los bebés y con ellos.

Palabras-clave: Investigación con bebés. Teatro con bebés. Estudios de infancia.

\section{Sobre o teatro infantil ${ }^{3}$}

Há pouco tempo, tive a oportunidade de assistir a um teatro infantil. Vieram crianças e me chamaram. As crianças interpretavam uma peça que aprenderam sob a direção da atriz A.Vassilieva.

Sabe-se que, em um espetáculo infantil, o adulto olha tanto para o público, quanto para a cena e pelo público pode com mais facilidade julgar se o que está ocorrendo em cena é bom e se está ou não atingindo o espectador. Um dos críticos fez assim: ao invés de escrever uma resenha sobre um livro infantil, publicou a opinião do seu pequeno filhinho sobre ele.

Então, o tempo todo pensei: se, seguindo este método, pudesse publicar - que acontecia nos rostos do público, quando o mais velho, provavelmente, tinha um pouco mais de dez anos, o tipógrafo teria que compor mais ou menos o seguinte - que interessante é o teatro infantil, na república infantil deve ter um subdepartamento no comissariado da interpretação (ou brincadeira) [...] (VIGOTSKI ${ }^{4}$ ).

Começamos este texto com um fragmento de uma das resenhas publicadas por L.S. Vigotski, no tempo em que viveu na cidade de Gomel, Bielorrússia, local que assumiria como sua cidade natal ${ }^{5}$ e onde vivenciou muitos movimentos envolvendo as experiências estéticas, sobretudo literárias e teatrais.

\footnotetext{
${ }^{3}$ A pesquisa foi aprovada pelo parecer, $n^{\circ} 2.574 .705$ e CAAE $n^{\circ} 81164817.3 .0000 .5243$ e financiada pela CAPES - Coordenação de Aperfeiçoamento de Pessoal e Nível Superior através de bolsa de doutorado e foi orientada pelo Prof. Dr. Jader Janer Moreira Lopes, coautor deste artigo. Todos os cuidados éticos sinalizados pela Plataforma Brasil foram atendidos, incluindo a autorização de utilização das fotos, pelas famílias.

${ }^{4}$ Resenha de L. S. Vigotski publicada em Nach Ponedelnik, n³5, de 07.05.1923, p. 3. Traduzida pela Profa. Dra. Zoia Prestes, 2018, especialmente para Pereira, 2018. Ver referência completa na bibliografia.

${ }^{5}$ Lembramos que Vigtoski nasceu em Orsha, também cidade da Bielorrússia, no dia 17 de novembro de 1896 , mas ficaria poucos meses aí, visto que logo sua família se mudaria para Gomel.
} 
Esta é, comumente, uma faceta desconhecida desse autor, que ficou muito mais conhecido, sobretudo para nós, brasileiros, pela constituição com seus grupos de Moscou da Teoria Histórico-Cultural. Contudo, a dimensão estética sempre foi algo fortemente presente na vida desse autor. Sua própria monografia “A tragédia de Hamlet, Príncipe da Dinamarca”, o livro "Psicologia da Arte" são exemplos de textos mais conhecidos desse autor no ocidente, mas há muitos outros materiais que evidenciam forte produção nesse campo.

Vladimir Sobkin (2017), em texto publicado no Brasil, responsável por organizar as resenhas teatrais escrita nos anos 20 , do século passado, apontará a importante relação entre esse momento e o valor para sistematizar a própria Teoria Histórico-Cultural.

As resenhas teatrais de Vigotski do período dos anos 1920 são pouco conhecidas para o leitor contemporâneo. Entretanto, elas têm um valor indubitável não apenas para a crítica da arte, como também para a psicologia. Nelas, expressam-se claramente as origens da psicologia não clássica e da concepção histórico-cultural que, mais tarde, será efetivada em suas investigações psicológicas fundamentais (SOBKIN, 20I7, p. 7).

A escolha por iniciar com essas narrativas envolvendo o autor bielorrusso se justifica pela escolha de escrita que irá se desdobrar no decorrer do próprio texto, inspirado em seus postulados. Assumimos, com esse autor e todo o grupo que fez parte da elaboração dessa outra forma de olhar o processo de humanização, que, para o plano social no qual vivemos, constitui-se como desenvolvimento cultural no humano, torna-se fundantes as acepções das relações recíprocas, que vão se materializando numa perspectiva de valorização do próprio humano em seu caráter autoral, desde o seu nascimento. É no COM que a vida vai se fazendo. Um com que emerge do campo social e pelas vivências, que é sempre relacional, se faz em cultura e singulariza cada um de nós. O próprio Vigotski (2000) assumiu isso em seus rascunhos que viriam a ser publicados como Manuscritos de 29:

\footnotetext{
A personalidade torna-se para si aquilo que ela é em si, através daquilo que ela antes manifesta como seu em si para os outros. Este é o processo de constituição da personalidade. Daí está claro, porque necessariamente tudo o que é interno nas funções superiores ter sido externo: isto é, ter sido para os outros, aquilo que agora é para si. Isto é o centro de todo o problema do interno e do externo. Compare o problema da interiorização em Janet e Kretchmer (Bühler): transferência da seleção, da experimentação para dentro (e com isso não percebem que a seleção produz a própria personalidade). Não é esta externalidade que nós temos em mente. Para nós, falar sobre processo externo significa falar social. Qualquer função psicológica superior foi externa - significa que ela foi social; antes de se tornar função, ela foi uma relação social entre duas pessoas. Meios de influência sobre si - inicialmente meio de influência sobre os outros e dos outros sobre a personalidade (s/p) (VIGOSTSKI, 2000, p. 24).
} 
Se, na contemporaneidade, muitas vezes, podemos nomear, de forma pessimista, esse pensamento utópico, em épocas marcadas por discursos que apontam como se a vida de cada um se acabasse nela, crer na vivência como marca coletiva é não só uma escolha ontológica e epistêmica, mas também a manutenção de uma resistência política.

No campo de estudos da infância e crianças, incluindo os bebês, não é diferente. A perspectiva formativa dos profissionais da educação infantil no nosso país continental está longe de assumir um projeto que assuma uma criança cidadã, que se enuncie, brinque, num espaço pedagogicamente organizado que propicie possibilidades de vivências, de encontros, de acontecimentos, de produção da vida, a vida enquanto uma escritura de criação do novo.

O campo das artes, dança, música, teatro e artes visuais, aparece nos documentos oficiais a partir da lei $n^{\circ} 13.278 / 16$. Mesmo com essa conquista, estamos, literalmente, engatinhando, quando nos reportamos à oferta de artes na educação infantil, incluindo os berçários.

Embora tenhamos avanços significativos no campo das artes e relação arte/educação, o tratamento dessas questões, no campo da formação em Pedagogia, é significativamente precário em virtude das escolhas curriculares e, principalmente, de subordinação política com vieses vinculados aos aspectos cognitivos, apressados e desrespeito à infância, enquanto categoria geracional permanente com base teórica na Sociologia da Infância.

$\mathrm{Na}$ epígrafe, Vigotski irá nos dizer da publicação da opinião da criança para o teatro e como isso o mobilizou a olhar para o rosto das crianças e, a partir de suas feições, publicar suas resenhas. Vigotski, sagazmente, já está nos dizendo na importância de reconhecer essas crianças, esse público, em que o mais velho teria um pouco mais de 10 anos de idade, como autores e críticos reflexivos daquilo que observavam.

Ao nos deparar com essa questão, inquirimos, a partir da nossa vivência com teatro adulto e infantil, mas, sobretudo, a partir da pesquisa para a dissertação de mestrado "Teatro para bebês, estreias de olhares" (PEREIRA, 20I4), uma conexão da arte, aqui representada pelo teatro, assumindoo enquanto uma atividade com os bebês, tendo por referência os conceitos e metodologias assumidas no teatro desde seu surgimento na Grécia por volta de 500 a.C.

Não, os bebês não fazem teatro, se levarmos em consideração a arte em seu aspecto racional e de intencionalidade estética, não, os bebês não fazem arte. [...] Assumimos uma posição política segundo a qual os bebês são seres da linguagem, que se forjam a partir dela e são produtores de cultura. Os bebês carregam uma aparente precariedade que é sua vantagem filogenética, humanizar-se pelo outro e humanizar o outro (PEREIRA, 20I8, p. 85).

Entendemos o teatro com bebês enquanto uma possibilidade de realizar uma atividade com base na técnica teatral, em que o(a) professor(a) oferte um meio pensado esteticamente para a 
atividade com os bebês; com cenário, adereços, uma dramaturgia que dialogue com a proposta estética com figurino e maquiagem, se possível, pensando a iluminação e a sonoplastia.

O meio ofertado, juntamente com a narrativa que convida os bebês a se enunciarem, a participarem da atividade, cada um no seu tempo. Essa atividade revela a herança cultural dos bebês, sobretudo, na relação com o outro bebê. São vivências propostas para o exercício de suas enunciações.

A vivência (perejivanie), conceito central da teoria histórico-cultural, consolida a proposta de um teatro com bebês.

A vivência é uma unidade na qual, por um lado, de modo indivisível, o meio, aquilo que se vivencia está representado - a vivência sempre se liga àquilo que está localizado fora da pessoa - e, por outro lado, está representado como eu vivencio isso, ou seja, todas as particularidades da personalidade e todas as particularidades do meio são apresentadas na vivência, tanto aquilo que é retirado do meio, todos os elementos que possuem relação com dada personalidade, como aquilo que é retirado da personalidade, todos os traços de seu caráter, traços constitutivos que possuem relação com dado acontecimento. Dessa forma, na vivência, nós sempre lidamos com a união indivisível das particularidades da personalidade e das particularidades da situação representada na vivência. Por isso, parece apropriado conduzir de maneira sistemática a análise do papel do meio no desenvolvimento da criança, conduzi-la do ponto de vista das vivências da criança, porque na vivência, como já coloquei, são levadas em conta todas as particularidades que participaram da determinação de sua atitude frente a uma dada situação (VIGOTSKI ${ }^{6}, 2010$, p. 686 -687, Grifos dos autores).

Podemos caracterizar os conceitos que assumimos para o escopo desta proposta de atividade, com base no conceito de unidade, inspirados em Espinoza.

Demonstramos que a mente está unida ao corpo porque este é objeto daquela (vejam-se as prop. 12 e 13). A ideia da mente, deve, portanto, pela mesma razão, estar unida ao seu objeto, isto é, à própria mente, da mesma maneira que a mente está unida ao corpo (SPINOZA, 2016, p. 66).

Esse conceito, que Vigotski assumiu na elaboração da Teoria Histórico-Cultural, aqui nos inspira a unir os conceitos de bebês, teatro, brincadeira e vivência, sempre levando em consideração a montante, enquanto nascedouros de possibilidades.

Assumimos os bebês como seres de linguagem e, a partir do campo de estudos bakhtinianos, a enunciação enquanto condição extraverbal. As crianças produziram suas vivências a partir da oferta de objeto, num arranjo cênico. Esse encontro permitiu ouvir suas falas e seus silêncios. As falas para si, a partir dos objetos e para o outro, falas enquanto balbucios.

Qualquer situação da vida que se organize uma enunciação, não obstante, pressupõe inevitavelmente protagonistas, os falantes. Chamaremos auditório da enunciação à presença dos participantes da situação. Cada enunciação da vida cotidiana, compreende,

\footnotetext{
6 Optamos por adotar a grafia do nome de Vigotski, embora haja diferentes grafias nas traduções brasileiras. Prestes (2012) adota como a melhor transliteração do russo para o português.
} 
além da parte verbal não expressa, também uma parte extra verbal não expressa, mas subentendida - situação e auditório - sem cuja compreensão não é possível entender a própria enunciação. Essa enunciação enquanto unidade significante, elabora e assume uma forma fixa precisamente no processo constituído por uma interação verbal particular, gerada num tipo particular de intercâmbio comunicativo social (VOLOCHÍNOV, 20I3, p. 159. Grifos do autor).

Assumimos as enunciações dos bebês a partir deste conceito, apoiamo-nos conceitualmente numa aproximação possível com o conceito de afiguração nos estudos pós-bakhtinianos:

... acerca da concepção estética de Bakhtin, podemos dizer que a obra artística sai do âmbito da representação. A obra artística, de fato, não considera as coisas como o eu diretamente as vê e as vive nos confins do próprio mundo, nos confins do próprio corpo individual, da própria arquitetônica, aquela que tem o eu como centro. [...] $\bigcirc$ mundo do eu não é visto como esse eu vê. $O$ autor não se coloca no seu lugar, não se coloca na sua pele, não se situa no centro da arquitetônica, identificando-se e compenetrando-se com tal centro. [...] A obra artística, ao contrário, do ponto de vista do outro, ou seja, daquele do autor-criador, revela a dualidade de um movimento dialógico. Essa não representa, mas exprime, afigura tal dialogicidade (PONZIO, 20I9. p. 5I.).

A propósito da escolha da palavra afiguração em itálico nas traduções do título, no conceito bakhtinianos, é uma palavra russa; a tradução italiana raffigurazione (IDEM, 2019, p. 5) foi cunhada atendendo os princípios dos estudos bakhtinianos e usamos em português com esse sentido.

A segunda contraposição é dada na dupla "representação" e "afiguração", que, em russo, são bem distintas (vosproizvedenie e izobraženie), e às quais Michail Bachtin na sua teoria da criatividade artística, endereça particular atenção fundamentalmente no que concerne ao estudo da literatura. A concepção bachtiniana se presta bem para ser colocada em relação e em diálogo com a pesquisa artística também no âmbito do visual e, em particular, relativamente aos nossos interesses, com a pintura. Isso não se deve tanto ao fato de que, na obra bachtiniana, se possam encontrar referências às artes visuais, ou ao fato de que a estética bachtiniana frequentemente amplie o próprio discurso, movendo-o do campo da literatura ao da produção artística em geral. A possibilidade de a pesquisa bachtiniana encontrar-se dialogicamente com a das outras artes depende muito do papel que a afiguração (izobraženie) desempenha em ambas, em contraste com a reprodução, a representação (vosproizvedenie), a imitação. Bachtin nega que a arte seja reprodução da vida, de modo que a obra seria somente duplicação, imitação da realidade, cuja função, o representar, seria apenas re-presentar, apresentar uma segunda vez. Então, para indicar aquilo que em russo é expresso por izobraženie, preferimos empregar a palavra portuguesa afiguração, não somente porque já existe no dicionário da língua portuguesa, mas também porque a inserção "forçada" de um neologismo como refiguração não nos permitiria fugir efetivamente da cilada semântica de remeter ao sentido de re-figurar, re-presentar, re-citar, re-calcar, e, então, novamente cair no conceito de representação (PONZIO, 2017, p. 21-22).

Assim, no cronotopo da pesquisa, tanto eu7 , que apresentava a atividade, quanto os bebês, éramos ao mesmo tempo, os mesmos e os diferentes. $O$ olhar que vinha do outro, o que enxergava

\footnotetext{
${ }^{7}$ Quando estiver falando na primeira pessoa, estarei falando no momento da pesquisa.
} 
no instante e o que a filmadora revelou posteriormente provocaram inúmeros deslocamentos. Os eixos de valores, que estavam planejados, ruíram e quase fiquei aprisionado num espaço/tempo que não dialogava com as enunciações dos bebês. As primeiras palavras que ecoavam, suas enunciações, eram os bebês afirmando para o outro a sua presença no mundo.

A obra artística cria um duplo: não, porém, no sentido da mimesis, mas da ambivalência. [...] A obra artística identidade reencontra a alteridade. Nesse sentido, ela cria um duplo. Recupera aquela espécie de Janus bifronte que é a experiencia intercorpórea... (IDEM, p. 52).

Entendemos o teatro com bebês tanto como uma proposta de atividade pedagógica no espaço da educação infantil, quanto uma obra de arte minuciosamente elaborada para o encontro das enunciações e afigurações dos bebês, ofertando um teatro numa perspectiva de convidarmos os bebês para uma "brincadeira elevada, ou seja, duas vezes mais interessante, e não uma nova narrativa do conto que ela compreende sem a representação" (PEREIRA, 2018, p.83 e 84 apud VIGOSTKI, 1923, p. 3).

\section{Encontro com os bebês}

A pesquisa foi realizada na Escola Nossa, da rede particular em Niterói-RJ, totalizando seis encontros, ocorridos entre maio e agosto de 2017. Aqui trazemos as contribuições do quarto encontro com os bebês realizado em 12 de julho de 2017, quarta-feira, ocorrido entre $15 \mathrm{~h} 40 \mathrm{~min}$ e $16 \mathrm{~h} 10 \mathrm{~min}$.

Nesse encontro, as crianças estavam desejosas para participar. Reafirmamos com a Prof. ${ }^{a}$ Ana Elisa que o objetivo da pesquisa era que, em cada encontro, houvesse a participação de quatro crianças. No entanto, havendo adesão e, se fosse possível, poderíamos realizá-lo com mais crianças. Chegamos, assim, ao número de seis crianças. Esse encontro, porém, se iniciou com oito crianças, ou seja, com duas a mais do que prevíramos. Helena (quarta vez), Miguel Jorge (segunda vez), Beatriz (terceira vez), Francisco (segunda vez), Miguel Rebelo (segunda vez), Josué (segunda vez) e as duas crianças não autorizadas para a pesquisa, Mohamed e Violeta. A presença dessas duas crianças, o que não fora previsto para a pesquisa, se deu por uma delas estar de saída da escola, com sua família indo morar no Oriente Médio e a outra estar em processo de adaptação na escola. Quando for me referir a elas, usarei os nomes fictícios de Mohamed e Violeta. Em suas aparições nas fotos, não aparecerão seus rostos. No decorrer da atividade, Violeta chorou e pediu para sair. Pedi a Josué, cujos movimentos energéticos constantes estavam dispersando o grupo, que fosse brincar com as outras crianças no parquinho. 
Teatro com os bebês: espaço de enunciações, afigurações e brincadeiras

$\mathrm{Na}$ sala do Infantil 2, espaço onde foram realizados os outros encontros da pesquisa, foi montado o cenário: encobri o piso completamente com o algodão cru, as paredes foram encobertas com voal preto transparente fixado com pregadores de roupa e a mala verde, em elemento constante em nossas narrativas, foi coberta com um tecido azul. Dentro dela estavam os adereços utilizados na narrativa. O figurino usado foi calça thai verde, bata indiana branca e meias. Sem maquiagem. Ao escrever as narrativas, optamos por diferenciar as falas dos bebês, que estão em negrito, das minhas, que estão em itálico.

Com tudo organizado, apesar das minhas orientações, nesse dia houve um atraso para iniciar a atividade. Como as crianças estavam focadas no lanche, demorou um pouco para que todas entrassem com a professora auxiliar Luana. Deixei a porta da sala aberta e Miguel Rebelo foi o primeiro a se interessar, ficando no umbral. Chamei-o para entrar:

- Miguel, entra, vem

Em seguida, Josué entrou correndo, sorrindo e se jogou no chão. Levantou-se, saiu novamente e retornou à sala, sempre rindo. Enquanto isso, Miguel Rebelo segurou o tecido voal preto que encobria as paredes da sala. Josué repetiu o movimento duas vezes, foi até perto de mim, não se jogou e correu para fora da sala. Nesse momento, alegre, entrou Mohamed, sentando-se na cadeirinha que a professora Luana faria a filmagem. Levantou-se em seguida e começou a andar pela sala.

- Vamos esperar os outros, eles já estão chegando - falei para os presentes.

Josué entrou e saiu mais uma vez da sala, uma das vezes empurrando um carrinho de bonecas e saindo em seguida. Cumprimento Miguel Jorge que havia chegado:

- Tudo bom?

Helena e Francisco, ao entrarem, foram direto para trás do tecido voal preto que encobria as paredes e ficaram rindo. Nos outros encontros, Helena descobrira o tecido na parede somente no final. Dessa vez, fora seu primeiro movimento na sala. Josué foi até eles pelo lado, falando:

- Heidiiiii tadiiiii eininimmm. Em seguida, começou a segurar o tecido.

- Josué, vem cá! - Chamei-o e escuto Francisco falar:

- Anannan.

Essa atitude do Josué fez com que Francisco desejasse sair. Quando se dirigia para a porta, encontrou Violeta. Em seguida conseguiu sair, sendo seguido por Helena. Pedi para que eles se sentassem. Mohamed passeava com alegria infinita pela sala. Finalmente, a professora auxiliar Luana entrou com Helena, Beatriz, Francisco e Violeta. Esta última, entretanto, começa a chorar, desejando sair, ficando, assim, sete crianças.

Após as idas e vindas das crianças na sala, resolvi começar o que já havia começado.

- Era uma vez... e paro pelo barulho de um tombo de Josué.

Olhar de professor, Ponta Grossa, v. 24, p. I-24, e-17609.02I, 202I.

Disponível em <https://revistas2.uepg.br/index.php/olhardeprofessor> 
Miguel Jorge estava sentado do meu lado e todos os demais em pé, Francisco olhando para os tecidos que encobriam a sala. As meninas silenciosas. Mohamed e Josué corriam pela sala e gritavam. Josué gritava de alegria:

- Aiaiaiiiiiiiiii - e esbarrando com força em Mohamed, caíram ambos no chão fazendo barulho. Isso chamou a atenção de todos. Eu, para chamar atenção, gritei aplaudindo:

\section{- Êêêêêêêêêêê.}

Josué repete:

\section{- Êêêêêêêêêêêê.}

Recomeço a narrativa:

- Era...

Josué pulou e se jogou de joelho ao lado da mala. Fiz uma pausa, olhei para ele e falei:

- Duas vezes! - emendando a frase que havia começando anteriormente.

Nisso Francisco disse:

\section{- Hiauam com medo.}

- Uma mala que tinha um monte de coisas - continuei. Miguel Jorge ficou curioso e se aproximou, ficando muito perto da mala. Retirando de dentro da mala uma pena de arara azul, falei:

- Um pássaro.

Josué e Mohamed estavam atrás do cenário correndo e rindo. Francisco, Helena, Beatriz e Miguel Rebelo estavam em pé, no canto direito em relação à porta, assistindo aos movimentos de Josué e Mohamed com alguma apreensão. Dirigi a pena de arara azul para eles e repeti com uma grande pena nas mãos:

- Um pássaro. E ele voou, voou, quem quer voar com o pássaro?

Josué e Mohamed continuavam rindo. Eu passei a pena em todos eles, falando:

- Pássaro voou.

Josué e Mohamed ficaram outra vez atrás do tecido que encobria as paredes, sendo seguidos por Francisco. Josué falava alegremente:

\section{- Aiam taataa ta.}

Enaquanto eu lhe passava a pena, ele repetia:

\section{- Aiam taataa ta.}

Ele puxava com interesse o tecido e, de repente, caiu.

- Eita. Vamos prá cá agora? - falei.

E Josué repetiu:

\section{- Aiam taataa ta.}

- Depois que o pássaro voou. 
Josué voltou a falar:

- Aiam taataa ta.

- O que foi que aconteceu?

Josué insistia em puxar o tecido e correr. Dei uma pausa. Não havia condições de prosseguir com a proposta com sete crianças. Assim, pedi para Josué ficar com as outras crianças no parquinho e assim ocorreu. Ele não gostou de ter que sair, chorou um pouco, mas conversamos e ele acabou saindo com a professora Ana Elisa. A dificuldade em organizar uma atividade que atenda a todas as crianças apareceu nessa situação.

A atividade continuou. $O$ ambiente ficou sem correrias com a saída de Josué e retornamos a viver num tempo mais lento. Miguel Rebelo pegou uma bucha vegetal grande de dentro da mala e falou:

\section{- Mamtamapa nata.}

- É, num é? Mostra pra elas - respondi e apontei para Helena e Beatriz que estavam em pé perto da mala.

Helena pegou a bucha. Beatriz saiu de perto e voltou em seguida, tocando na bucha e curiosa com o que eu estava mostrando. Miguel Jorge, muito curioso, insistia em abrir o zíper da mala que eu, discretamente, fechava cada vez que ele abria. Ele insistia em encontrar a forma de abrir, mas não tinha força para realizar seu desejo.

Peguei o cesto onde estavam guardadas as palavras dentro da mala e falei:

- Vou mostrar pra vocês uma coisa, aqui é onde guardamos as palavras.

Nisso, Miguel Rebelo falou:

\section{- Êêêtaaaa.}

- As palavras são guardadas aqui AAAAAAA. (figura 0I) - continuei.

Todos prestaram atenção naquele momento e ficaram bem juntinhos de mim, rindo.

- Caa vaa loo. A cada sílaba enunciada, Miguel Jorge ria muito. Mohamed pegou o cesto, foi observar a saída das palavras e repetiu:

- AAAAAAAAAA.

- Vamos ver o que tem mais aqui dentro? - Continuei. 
Figura 0 I - O cesto das palavras - 2017

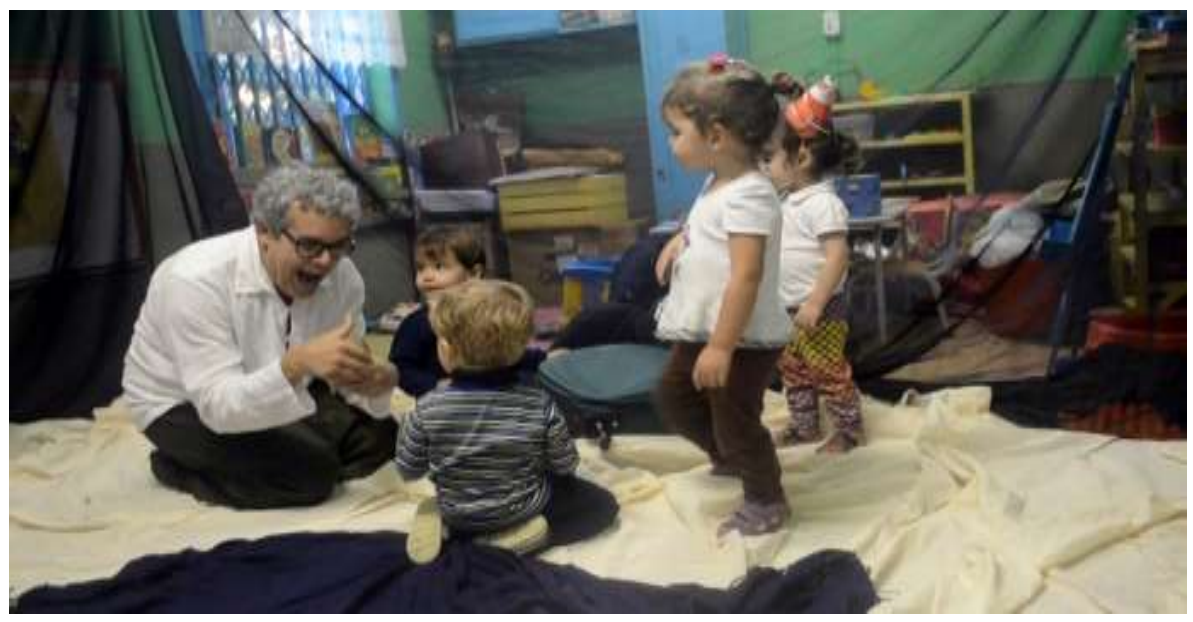

Fonte: Acervo do autor - Frame da filmagem, 2017-

Enquanto isso, Beatriz se interessava pelo tecido preto do cenário e Miguel Rebelo, Helena e Miguel José olhavam curiosos para o que mais iria sair da mala.

- Vamos lá!

Mohamed repetia o AAAAAAAA, dando a entender "vamos!" e o som de ecoava na sala.

- Uma máscara! - Digo, pego a cuia de coco furada e olho através do buraco no fundo.

A curiosidade se presentificou e passeou pelo rosto de Miguel Rebelo e depois de Helena de quem aproximei a máscara (figura 02). Enquanto isso, Miguel Jorge tentava abrir a mala em busca de outras novidades.

Figura 02 - Apresentando a máscara - 2017

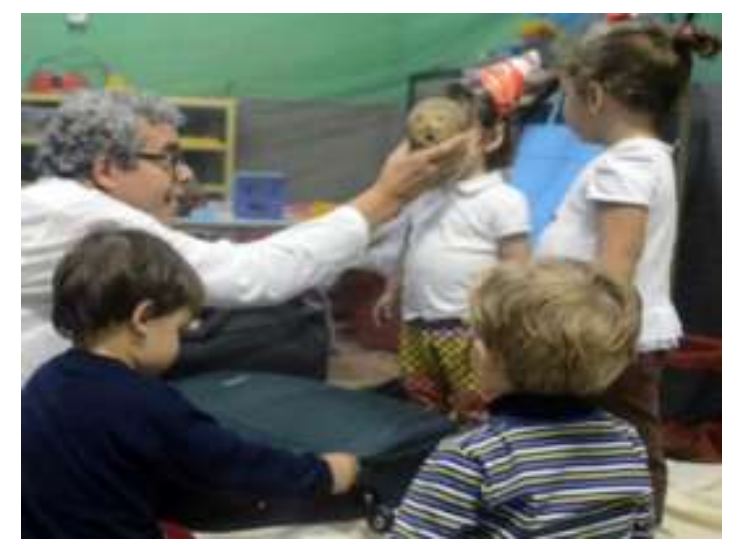

Fonte: Acervo do autor - Frame da filmagem, 2017.

Beatriz e Rebelo olhavam para a máscara em Helena. Voltei para a narrativa:

- Tem outra aqui dentro, tem duas máscaras! 
Mohamed, que estava com o cesto das palavras, ao ver as duas máscaras, largou, sem nenhum apego, o cesto de palavras no chão e correu para cima da mala para pegar as duas máscaras. Fiz um jogo com as mãos, ele pegou uma das máscaras. Comecei a chorar imitando o som que saía da cesta:

- AAAAAAA.

- BBBBB.

Em seguida, peguei a máscara e olhei para as demais crianças. Rebelo, Beatriz e Beatriz riam da cena. Miguel Jorge insistia em tentar abrir a mala em busca de novidades. Deixei a máscara no chão e peguei o cesto de palavras que estava perto e voltei à brincadeira. Abri o cesto, falando alto:

- $A A A A A A A$.

Deixei o cesto aberto. Mohamed começou a brincar com a máscara que pegara e a repetir os movimentos de olhar através do buraco. Segurava como uma preciosidade, até enxergar o próximo interesse.

- Vou fechar senão as palavras vão embora - disse, fechando o cesto de palavras e deixando-o no chão perto da mala. Miguel Rebelo, Miguel Jorge e Mohamed endereçaram olhares para o cesto. Mohamed se agachou, pegou para si o cesto, largando a máscara de coco.

Retirei da mala uma caixa colorida que guardava o que tinha sobrado do carrossel, a base, que era a caixa de música.

- Isso aqui é lindo, vamos lá...

Miguel Rebelo, Miguel Jorge, Beatriz e Helena ficam em torno da mala para olharem a caixa. Rebelo disse:

- ULÁÁÁÁ - me imitando. Ao ouvir o som da caixa de música, falou:

- UAAAAAAAA.

Figura 03 - Beatriz pega a caixa de música - 2017

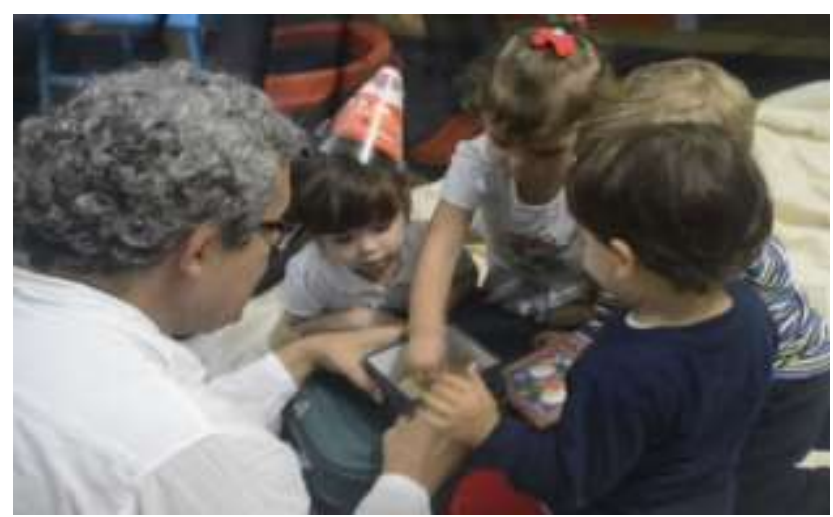

Fonte: Acervo pessoal - Frame da filmagem, 2017.

Beatriz, prontamente, pegou a caixa de música, dizendo:

- Teia, teiaa (figura 03). 
O som da caixa de música ecoava pela sala. Os sons ouvidos na sala eram as palavras de minha narrativa, da comunicação das crianças, momentos de enunciações quase silenciosas.

Deixando livre a caixa para quem quisesse pegá-la, Miguel Jorge a pegou para si. Mohamed se interessou pela pena azul. Isso, na filmagem, aparece como um pássaro que deseja se aproximar dos seus pares.

Todas as vezes que eu retirava um adereço da mala, fechava imediatamente. Miguel Rebelo era o único que percebia essa ação. Tentava abrir o zíper, mas não conseguia, pois não tinha força. Ele mostrava certo interesse pelo que era mostrado, logo depois voltava a se interessar pelo zíper da mala.

- Vamos ver mais?

- Maiss - respondia Rebelo.

- Vamos ver mais? Deixa a música acabar.

Mohamed se dirigiu para o grupo sentado em torno da mala e pegou a caixa de música das mãos de Beatriz. Seu interesse foi notado por todos que olharam para ele curiosos. Rebelo, imediatamente, segurou também a caixa junto com Mohamed e, numa disputa de força, conseguiu ficar com ele depois do intenso jogo de interesses. Beatriz tentava entrar no jogo em vão.

- Vamos ver o que tem mais aqui- apresentei-Ihes uma pequena alfaia.

Gritos de alegria ecoavam na sala. Mohamed imediatamente se dirigiu para o grupo e subiu na mala em busca do adereço.

- Ele não quer sair daqui- falei, segurando a alfaia com firmeza, tocando com os dedos e produzindo um som tribal.

Mohamed se apossou da alfaia e, ao mesmo tempo, da caixa que guardava a caixa de música. Miguel Jorge falou:

- Miiidá! - ele repetiu outras duas vezes com muita ênfase, conseguindo manter a caixa consigo.

- Vamos ver o que tem mais aqui!

As crianças se debruçaram sobre a mala da qual retirei uma boneca andina.

- Uneca! - falou Rebelo (figura 04).

Ao ouvir essa palavra, perguntei:

- Como é o nome?

- Uneca!

Miguel Jorge, que já abandonara a caixa, tentava a todo custo abrir a mala. Mohamed se dirigiu para cima da mala para pegar a boneca e eu parei tudo para conversar com ele:

- Mohamed, você estava com a alfaia - mostrei para ele e continuei - a boneca vai falar. 
Figura 04 - Apresentando a boneca andina - 2017

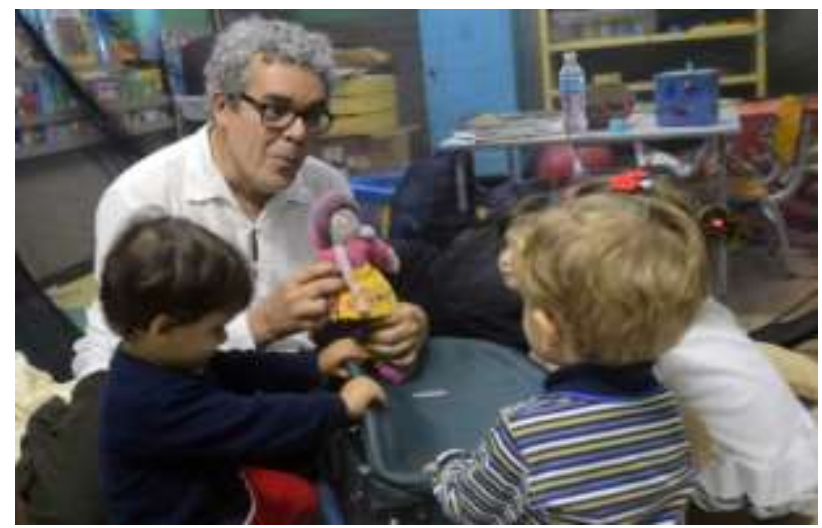

Fonte: Acervo pessoal - Frame da filmagem, 2017.

Beatriz pegou na trança da boneca, Rebelo pegou-a e botou-a no chão. Beatriz ficou olhando para ela com atenção, voltando-se curiosa para saber o que ainda havia dentro da mala.

Ofereci a Miguel Jorge a chance de ele abrir o zíper da mala e Miguel Rebelo falou:

- Abi, abi (figura 05).

Como Miguel Jorge não estava conseguindo abrir, Miguel Rebelo pegou o zíper e abriu.

- Isso! vamos ver o que tem mais aqui.

- Mais! - Rebelo continua.

O enunciado de Rebelo representava o desejo de todos que pareciam querer dizer: "Abre que queremos ver o que tem dentro dessa mala, acabar com esse mistério".

Retirei de dentro da mala um conjunto de caixas no estilo da matrioska (boneca russa). Os sons das vozes de Rebelo e Miguel Jorge contrastavam com o silêncio de Mohamed e, sobretudo, de Beatriz e Helena.

Miguel Rebelo continuava a enunciar seus fonemas:

\section{- Anamais!}

Figura 05 - Rebelo e o zíper da mala - 2017

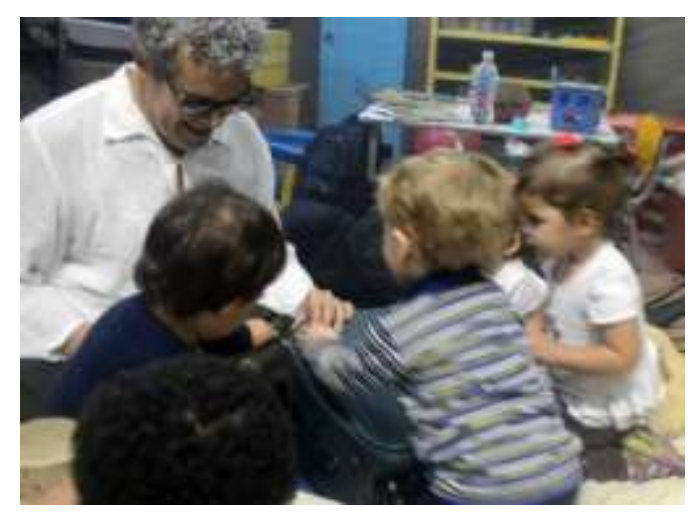

Fonte: Acervo pessoal - Frame da filmagem, 2017. 
Nessa hora, a caixa ficou sobre a mala e falei:

- Caixa! - abrindo a caixa maior, falei:

- Outra caixa!

Nesse momento, todos estavam em volta da mala. Mohamed se dirigiu para pegar as caixas para si.

- Espera um pouquinho - falei, destampando a caixa e pedindo para Miguel Rebelo colocar a caixa maior do lado dele.

- Bote essa pra lá, por favor! - contínuo - outra caixa!

Pedi para Mohamed levar as caixas já abertas para perto dele. Fazendo-o, ele voltou imediatamente para segurar as demais. Beatriz tirou a tampa de uma das caixas. Todos observavam o movimento, embora Mohamed estivesse interessado em pegar para si todas as caixas. Assim, como num passe de mágica, as caixas foram sendo abertas por Rebelo, Beatriz e Mohamed.

- Outra caixa, outra caixa, outra caixa.

Pronto: o alvoroço e a alegria das crianças pelas caixas foram instantâneos. Rimos muito. Beatriz e Helena olhavam para o meu rosto e riam de minha risada, um momento de muita alegria. As vozes de Rebelo se misturavam com o seu riso, provocando sons de bem quereres.

A curiosidade de todos voltava-se para o conteúdo da mala.

- Vamos ver o que tem mais? Vamos? Deixa eu fechar para abrir de novo. Pronto, abre - falei, dirigindo-me para Miguel Jorge.

Rebelo disse:

- Abi.

Mohamed tomou à frente e foi pegar o zíper para abrir, empurrando Miguel Jorge.

- Deixe ele abrir, por favor, Mohamed - interferi.

Ele abriu até a metade e Mohamed o restante da mala. Miguel Jorge reclamou:

- Naaadaaaaa - parecendo argumentar que seria vez de ele abrir a mala.

- Cuidado para não machucar a mão.

Rebelo falou:

- Abe, abe, abiu.

Retirei de dentro da mala uma boneca pequena que pouco causou interesse. Estendi até Beatriz que a segurou. Helena permanecia muito silenciosa ao lado da mala, como se aqueles movimentos lhe causassem bem-estar. Voltei a falar:

- Vamos fechar para abrir de novo?

O interesse em abrir a mala era muito grande. Rebelo insistia em falar:

- Abe, abe.

Olhar de professor, Ponta Grossa, v. 24, p. I-24, e-17609.02I, 2021.

Disponível em <https://revistas2.uepg.br/index.php/olhardeprofessor> 
Miguel Jorge e Mohamed disputavam a primazia de quem iria abrir. Como ficou difícil para eles, ajudei Miguel Jorge, que falou:

\section{- Tá duro!}

- Tá duro, num tá?

Mohamed chegou primeiro e abriu a mala. As cabecinhas se debruçaram para conseguir enxergar os mistérios da mala.

- Vamos ver o que tem mais! - falei, retirando o candeeiro e acendendo-o - a luz! (figura 06).

Fechei muito rápido a mala, enquanto eles estavam envolvidos com a luz que eu tinha acendido. Beatriz pegou para si o candeeiro. Muhamed tentou pegar também, mas deixou escapar. Ela fica acendendo e apagando, enquanto Helena e Rebelo ficam olhando. Miguel Jorge e Mohamed voltaram a atenção para a mala:

Figura 06 - Candeeiro aceso - 2017

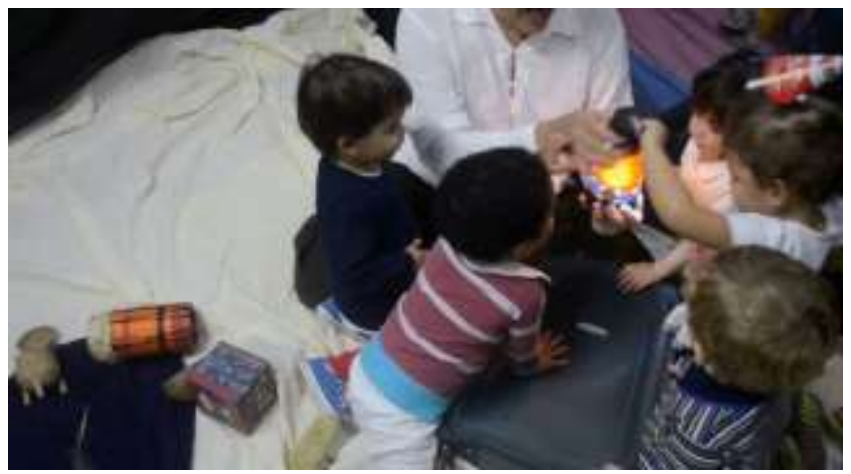

Fonte: Acervo pessoal - Frame da filmagem, 2017.

- Vamos ver o que tem mais - falei, retirando, por uma pequena abertura da mala, um colar de argila. Mohamed, imediatamente, estirou a mão para pegá-lo, puxando com força. Entrego-lhe o colar e, segundos depois, ele se desinteressou, largando-o no chão e voltando a atenção para o que ainda iria sair da mala.

- Vamos abrir de novo?

Rebelo insistia:

- Abe, abe.

Retirei um pneu pequeno que Mohamed tentara tirar de minha mão, segurei-o com força, apresentando-o para Helena. Mohamed voltou a atenção para o colar. Beatriz continuava encantada com o candeeiro. Miguel Rebelo e Miguel Jorge querendo abrir a mala para ver o que havia dentro. Assim, retirei o livro "a mala de fugir". Mohamed esticou o braço e pegou imediatamente o livro. Miguel Jorge, praticamente entrando dentro da mala, falou: 
- Acabô.

Peguei também uma bola de festa azul vazia e furada. Embora chateado e triste, Miguel Rebelo pegou a bola.

- Vamos abrir de novo?

Miguel Jorge disse:

- Acabô.

Eu, dizendo que ainda havia alguma coisa lá, segurei, fechando a mão. Passei de uma mão para outra, ainda fechada, apresentei para Miguel Jorge e Mohamed que não se interessaram. Helena e Beatriz ficaram atentas. Beatriz tocou o dedinho, vou abrindo a mão lentamente e falei:

- Fugiu, foi-se embora.

Enquanto isso, Mohamed pegou o candeeiro e Miguel Jorge observava, atento e pronto para pegá-lo para si. Miguel Rebelo falou:

\section{- Atai, atai.}

Como não consegui entender exatamente o que ele queria, supondo que estaria pedindo para fechar a mala, falei:

- Vamos primeiro abrir totalmente a mala.

A mala estava finalmente aberta e todas as curiosidades quase sanadas. Miguel Jorge, com o candeeiro, falou:

- Luz! abiu! - disse Miguel Rebelo.

- Agora vamos guardar de novo? Um a um? Quem me ajuda?

Mohamed colocou uma tampa dentro da mala e eu disse:

- Vamos guardar direitinho.

Rebelo encontrou o colar e ficou com ele. Beatriz tomou a iniciativa de recolher os objetos. Peguei a caixa de música, dei corda e o som se espalhou pelo espaço da sala. Nesse momento, todos estavam ocupados com seus interesses, num instante poético. Cada criança enunciava sua vida nas vivências que esse momento propiciou. Os que não falavam conseguiam emitir sons com intencionalidades. Nesse encontro, Helena e Beatriz pouco falaram ou quase nada, Mohamed também, embora tenha um corpo potente de desejo pela novidade. Miguel Rebelo falou muito e Miguel Jorge foi movido pela curiosidade, por algumas falas e alguma quietude. Beatriz encontrou um livro e começou a manuseá-lo com elegância de estilo (figura 07). Mohamed se interessou pelo candeeiro que estava com Miguel Jorge e começou a disputá-lo, até que a alça ficou na sua mão, falando:

\section{- Atattaaa.}

- Deixe eu arrumar - eu disse para eles, recolocando a alça no candeeiro. 
Beatriz continuava arrumando os objetos para guardar na mala. Helena decidiu também guardar os objetos. Pegou a maior caixa sem a tampa, levou-a para dentro da mala, depois a tampa, a bucha natural, as outras caixas e assim foi levando para dentro da mala os objetos. Mohamed e Miguel Jorge desejavam o candeeiro e este último falou:

Figura 07 - Beatriz e o livro - 2017

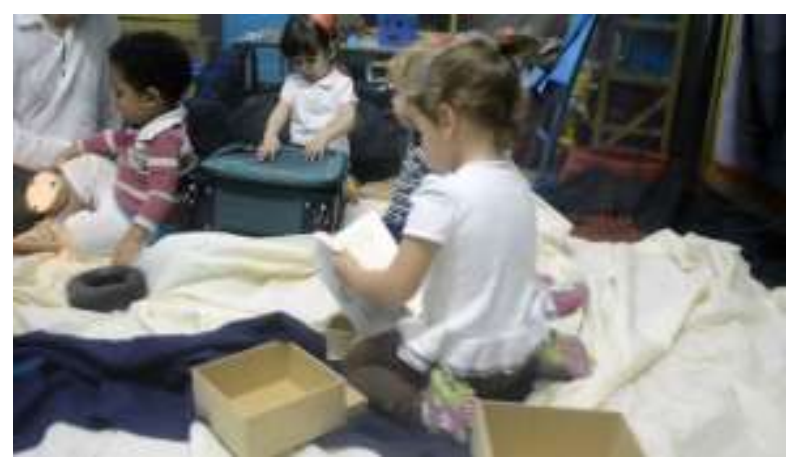

Fonte: Acervo pessoal - Frame da filmagem, 2017

- Sota, abuia, soooo - gritando argumentava - Soota! (figura 08).

Miguel Rebelo estava interessado pela alfaia e Helena pelo cesto de palavras. Interferi na disputa falando:

- Mohamed, tem muitos brinquedos aqui.

Rebelo falou com a alfaia na mão:

- Kalund, kaland, abiiii, abi - apontando a alfaia para mim.

Figura 08 - A disputa pelo candeeiro - 2017

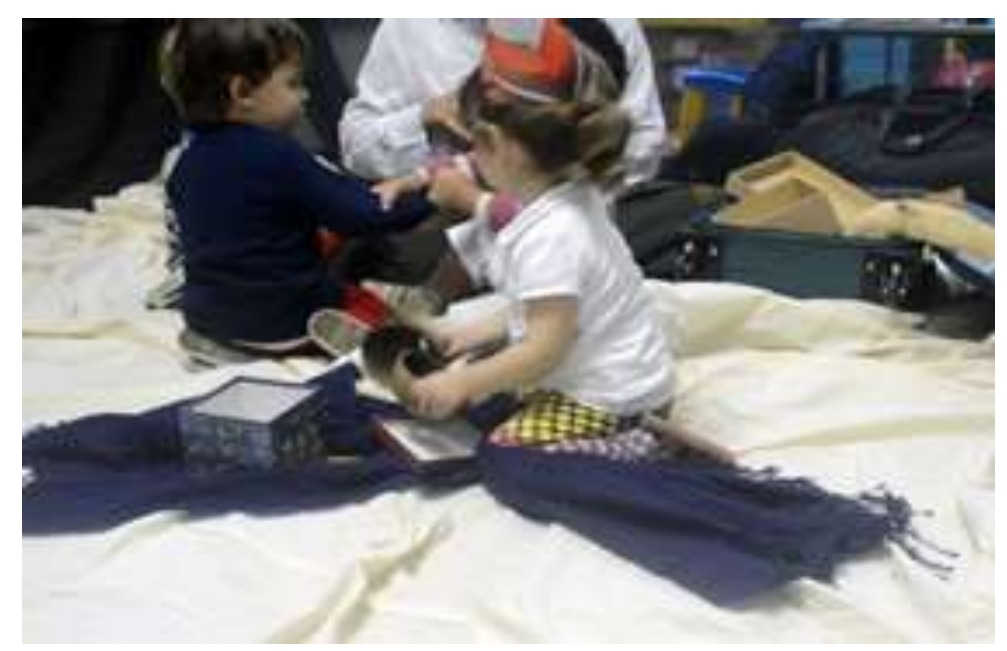

Fonte: Acervo pessoal - Frame da filmagem, 2017- arquivo pessoal

- Não abre! É pra tocar - respondi, tamborilando com os dedos e mostrando para ele. 
Beatriz encontrou a boneca andina e segurou-a com esmero. Helena foi levando os objetos para a mala. Mohamed segurava o candeeiro, Rebelo ria, segurando a alfaia e falando:

- Abi, abi!

Miguel Jorge tocou na alfaia, dizendo:

- Foça!

Diante daquele momento poético, eu ria. Em seguida, voltei a atenção para Miguel Jorge e falei:

- Força!

Toquei na alfaia produzindo sons. Mohamed se interessava em tocar a alfaia e estendia o braço para o couro da alfaia, tocando-a.

- O que mais vamos botar aqui dentro? - falei, apontando para a mala.

Mohamed tirou da mala a bucha natural. A alfaia foi abandonada por Miguel Rebelo que estava com a caixa de música. Dei corda dela e o som se espalhou pelo espaço. Peguei o pneu e empurrei-o pela sala. Miguel Jorge correu atrás dele rindo e pegou-o. Os sons quase incompreensíveis que emitiam revelam sua comunicação, sua presença no mundo pela oralidade. Repeti a cena do pneu e Miguel Jorge gritava com alegria. Mohamed, antecipando-se, pegou o pneu e, imediatamente, ele gritou:

\section{- Nããããoooo!}

Ele gritou colocando o pneu dentro da mala. Miguel, rindo, retirou de dentro da caixa afirmando que queria brincar com ele. Depois dessa cena, Mohamed pegou o colar de argila e se dirigiu para o tecido preto transparente que envolvia as paredes. Helena encontrou a bucha vegetal, Beatriz ainda continuava com a boneca andina e Miguel Rebelo se divertia com a caixa de música. Peguei o cesto de palavras e repeti a cena das palavras que fogem falando de dentro do cesto:

\section{- Aaaaaaaaaa.}

Essa ação chamou atenção de todos que riram. Miguel Rebelo se interessou pelo cesto, abrindo-o e fechando-o, enquanto eu emitia o som da fuga das palavras (figura 09). Miguel Jorge pegou o cesto das mãos de Rebelo e, ao abrir a tampa, emitiu o som:

- Aaaaaaaa - repetindo algumas vezes.

Beatriz, totalmente envolvida com a boneca andina, disse:

\section{- A neném!}


Figura 09 - Palavras saindo da cesta: Aaaaaaaaa!

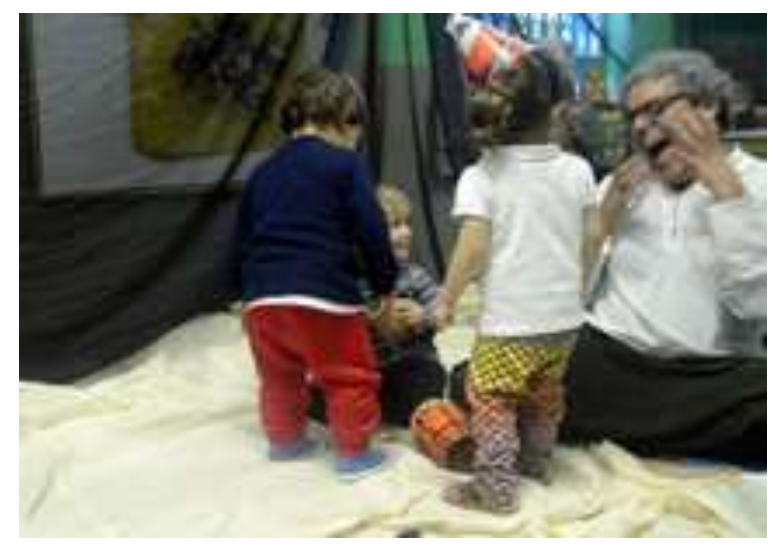

Fonte: Acervo pessoal - Frame da filmagem, 2017.

Ela continuava explorando os detalhes da boneca, roupas, sapatos com ela no colo. Enquanto isso, Mohamed explorava para além do espaço cênico, para o espaço que eu separara e que continha os materiais da sala. Ele parecia gostar de estar lá. Pedi-lhe que voltasse, mas parecia que ele estava achando tudo muito agradável.

- O que mais que a gente pode botar dentro da mala, acabou?

Helena sentou-se perto de Beatriz e abriu o livro, folheando as páginas com atenção. Miguel Jorge, ao reencontrar o pneu, falou:

- Papá, papá. - Numa referência clara ao pai e ao seu automóvel.

Convidei-os a guardar os objetos na mala.

Enquanto isso, as bolas de festa que estavam sob o cenário que cobria $\circ$ chão foram encontradas e as crianças ficaram alegres com aquela surpresa.

-Assei - Miguel Jorge falava alegremente.

- A BOLHA, BOLHA, BOLA - esse som era emitido por todos.

A bola de Miguel Jorge estourou e ele me passou o que sobrou.

- Vamos procurar, tem mais.

Rebelo, que estava com duas bolas, ofereceu uma mais murcha para Miguel Jorge:

-Addtem addtem - falava ele.

Como Miguel Jorge queria a maior, começou a gritaria. Foi difícil resolver essa situação. Mohamed interferiu, jogando uma das bolas para longe e a gritaria continuava sem solução, até que chamei Miguel Rebelo e entreguei uma bola para ele. Mesmo assim, Miguel Jorge queria também a bola de Miguel Rebelo. Quando, finalmente, encontrou uma, falou:

- Achei. 
Depois da festa com bolas, fomos recolhendo os objetos, enquanto as crianças se movimentavam pelo espaço até que foram todas para atrás do tecido que encobria a parede. $O$ pano se desprendeu dos pregadores e elas se enroscaram nele no chão rindo muito.

Eles ajudaram a desmontar o cenário. A leveza do tecido atraiu as presenças de Mohamed, Miguel Rebelo e Miguel Jorge. Beatriz e Helena se aproximavam dos objetos para guardá-los e ficar um pouco com eles. Helena explorou o cesto de palavras, abriu, mas não saiu nenhuma palavra de dentro dele.

\section{- Eeeeaaaassssuuuuu - falava ela para Beatriz.}

Beatriz empilhou a alfaia e a caixinha de música do ex-carrossel para guardar dentro da mala.

Nesse momento, Beatriz e Helena foram para dentro do tecido preto. Helena pegou uma bola. Como Miguel Jorge intencionou levantar-se para pegar a bola dela, imediatamente, ela entregou-a para ele. Assim, abri a porta da sala. Logo depois, eles foram chamados pela professora para brincarem no parquinho. Agradeci às professoras, despedi-me das crianças. Terminei de desmontar o cenário, guardei os objetos de cena, tirei o figurino e voltei para casa com aquela sensação de não dar conta da pesquisa que estava fazendo, era muita intensidade, muita entrega. Meus inacabamentos me impossibilitavam, naquele momento, qualquer reflexão, deixando, para bem mais tarde, assistir aos vídeos, fazer a transcrição e, algum tempo depois, com um olhar mais alargado de quem estava com as crianças e também era assistido por elas, ao mesmo pela câmera, construo esta narrativa.

A brincadeira, a repetição, o entusiasmo, a surpresa, a descoberta, o diálogo, a disputa, a alegria, o silêncio, o grito, o movimento, ficar sentado, entre outras ações, provocam-nos a pensar num teatro com bebês que permita essas possibilidades aos bebês, numa situação social de desenvolvimento que é, também, estético.

\section{Inacabamento}

A questão para o adulto é extremamente difícil e provocou uma grande polemica na literatura pedagógica russa: devem as crianças interpretar ou brincar de teatro e como. Tenho fortes dúvidas a respeito do fato de que os rostos infantis tenham vantagem por causa de uma simples maquiagem, e também por causa de o conto de fadas meloso e a bobagem de crocodilo se configurarem no único material para o teatro e a literatura infantis. Existem países inteiros de seriedade infantil e de brincadeiras profundas. Olhem, como a criança brinca com seriedade.

E mais: o teatro para crianças ou teatro das crianças. Numa palavra - para o adulto existe um monte de questões pedagógicas, artísticas, um monte de dificuldades e dúvidas insolúveis naquilo que é denominado teatro infantil.

Porém, para a criança, está tudo decidido e tudo claro: o teatro para ela é uma brincadeira elevada (ou seja, duas vezes mais interessante), e não uma nova narrativa do conto que ela compreende sem a representação. E como é bom que as crianças não se interessam por questões pedagógicas. 


\begin{abstract}
Dessa vez, quero estar nesta questão junto com as crianças. Pode ser que isso não seja inteligente para o adulto, mas pelo menos é divertido. $E$ já que é interessante (e terrivelmente interessante!), então cuidem para que existisse o teatro infantil (já existem livros, canções, quadrinhos para crianças); para que ele fosse atencioso e melhor em relação às crianças do que aquele espetáculo no qual eu estive e que as crianças assistiram suspensas no ar: que desse à criança o que ela precisa e o que ela pode.
\end{abstract}

Existem possibilidades externas para isso. Há tantos círculos de dramatização nas escolas, quantos espetáculos. Não precisa procurar as crianças prodígio, mas inventar e organizar uma vez num certo tempo uma grande brincadeira para as crianças. É preciso semear não apenas “o racional, a bondade, o eterno”, mas cuidem de alguma forma também do divertido, do ócio, do interessante. Ponham sal do pedacinho de pão para a criança, senão fica insosso e seco - sal de rizo e lágrimas, sal do teatro. (PEREIRA, 2018, p. 83 e 84, apud VIGOTSKI, 1923, p. 3).

Começamos este artigo com um fragmento da resenha de Vigotski e vamos terminálo trazendo também o final dessa resenha, que, mesmo sendo "aparentemente" curta, traz pontos de grande potência. É importante destacar que ela foi escrita em 1923 e traz aspectos bem contemporâneos que hoje debatemos no campo de Estudos da Infância.

Há questões que ele levanta que nos leva a reflexões, sinaliza para a dificuldade de uma proposta teatral de crianças com a pergunta: "devem as crianças interpretar ou brincar de teatro e como?"

Ele responde:"Porém, para a criança, está tudo decidido e tudo claro: o teatro para ela é uma brincadeira elevada (ou seja, duas vezes mais interessante), e não uma nova narrativa do conto que ela compreende sem a representação" (op. cit. 2018).

A brincadeira, portanto, está indissociada ao teatro com bebês. Vigotski sempre marcou a importância dessa atividade humana no próprio processo de desenvolvimento e de humanização. Para ele, o brincar não pode ser reduzido a um momento simples e sem valor, como às vezes é preconizado em algumas situações, mas tem uma força enunciadora do novo, quer seria a grande marca do humano. Em suas palavras:

A brincadeira da criança não é uma simples recordação do que vivenciou, mas uma reelaboração criativa de impressões vivenciadas. É uma combinação dessas impressões e, baseado nelas, a construção de uma realidade nova que responde às aspirações e aos anseios da criança. Assim como na brincadeira, o ímpeto da criança para criar é a imaginação em atividade. (VIGOTSKI, 2009, p. I7)

Como apontamos no início, foram essas inspirações que nos mobilizaram, que forjaram o fazer neste trabalho. Esta pesquisa revelou uma perspectiva de aproximar o teatro dos bebês, mas não no sentido do espectador passivo que se apoia no aspecto sensorial, mas na dimensão 
da participação frenética da oferta de uma poética teatral que dialoga com a teatralidade do humano. "Considero o teatro uma forma primeira e especial do ser humano, assim como o desejo que o ser humano tem de ser livre" (VANNUCCl, 20II, p. 91) Assim, estamos inaugurando um movimento de apropriação de um teatro com os bebês. Repensar o teatro a partir dos nascimentos, dos pequenos, aqueles dos berços e berçários. As contribuições dos bebês para pensarmos outras perspectivas teatro são inimagináveis, tendo esta pesquisa contribuído com uma possibilidade.

Engatinhamos em busca da potência desse teatro, que se evidencia a partir dos processos de inacabamentos, incertezas e, principalmente, na permanente busca por uma proposta de humanização através da arte e, através dos encontros e desencontros, nos quereres e não quereres, naquilo que desejo e abandono imediatamente, assim que surge uma novidade diante dos olhos.

Os bebês estão chegando ao mundo para transformá-lo! O encontro com eles é marcado pela nossa responsabilidade de promovermos um meio social de desenvolvimento que corrobore com essa urgente necessidade de se refazer o mundo.

Vigotski nos diz na epígrafe: “[...] quero estar nesta questão junto com as crianças”. E, nós, em nossa escolha ética e responsiva (BAKHTIN, 2017), também temos esse desejo. Poderíamos fechar este texto com a tradicional frase que circula em nossas vidas cotidianas, então “Mãos à obra!”, mas, como estamos no COM, fica o convite: o “Mãos à obra, como metáfora do corpo inteiro e como concepção de que o plural “mãos" é o encontro de muitas delas, adultas, de crianças pequenas e de bebês.

\section{REFERÊNCIAS}

BAKHTIM. M.M. Para uma filosofia do Ato Responsável. São Carlos: Pedro \& João Editores, 2017.

BRASIL. Lei $n^{\circ} 13.278$, de 2 de maio de 2016. Altera $\circ \S 6^{\circ}$ do artigo 26 da Lei $n^{\circ} 9.294 / 96$, referente ao ensino da arte. Diário Oficial da União, Brasília, 2016. <Disponível em: http://www.planalto.gov.br/ccivil_03/_Ato20I5-20I8/20I6/Lei/LI3278.htm > Acesso em I2 fev. 202I.

PEREIRA, L. M. Teatro com bebês, enunciações e vivências: encontros da arte com a vida. Tese (Doutorado em Educação). Niterói, RJ. Faculdade de Educação, Universidade Federal Fluminense 2018.

PEREIRA, L.M. Teatro com bebês, estreia de olhares. 20I4. Dissertação (Mestrado em Educação) Universidade Federal Fluminense. Niterói-RJ. Faculdade de Educação, Universidade Federal Fluminense. 2014. 
PONZIO, L. Ícone e afiguração: Bakhtin, Malevitch, Chagall. São Carlos: Pedro \& João Editores. 2019.

PONZIO, L. Visões do texto. São Carlos: Pedro \& João Editores. 2017.

PRESTES, Z. R. Quando não é quase a mesma coisa: análise de traduções de Lev Semionovitch Vigotski no Brasil: Repercussões no campo educacional. Campinas, SP: Autores Associados, 2012. Coleção educação contemporânea.

SOBKIN, V. As resenhas teatrais de L.S. Vigotski como início da concepção histórico-cultural. In: VERESK - Cadernos Acadêmicos Internacionais- Estudos sobre a perspectiva históricocultural de Vigotski. Brasília: UniCEUB, 2017.

SPINOZA, B. de. Ética / Spinoza; [tradução de Tomaz Tadeu]. - 2. ed., 5. reimp. - Belo Horizonte: Autêntica Editora, 2016.

VANNUCCI, A. O teatro como instrumento de liberdade in: org. Prado. A.L. A teatralidade do humano. São Pauo, Edições Sesc, 20I.

VIGOTSKI, L. S. Quarta aula: a questão do meio na pedologia. Tradução de Márcia

Pileggi Vinha. São Paulo: Psicologia USP, 2010.

VIGOTSKI, L.S. Imaginação e Criação na infância. Trad. Zoia Prestes. São Paulo: Ática, 20 I0.

VIGOTSKI, L.S. Manuscrito de 1929. Trad. Alexandra Marenitch. Educação \& Sociedade, ano XXI, $n^{\circ} 7 \mathrm{I}$, julho/00, disponível em: https://www.scielo.br/scielo.php?script=sci_arttext\&pid=SOI0I 73302000000200002 Acesso em: 20 fev. 2021.

VOLOCHÍNOV, V. N. A construção do enunciado e outros ensaios. São Carlos: Pedro \& João Editores, 2013.

Recebido em: 12 de março de 2021 .

Versão corrigida recebida em: 15 de março de 202I.

Aceito em: 17 de março de 2021.

Publicado online em: 26 de março de 2021 .

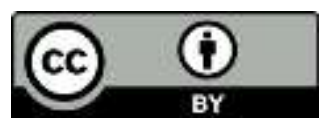

Olhar de professor, Ponta Grossa, v. 24, p. I-24, e-17609.02I, 2021.

Disponível em <https://revistas2.uepg.br/index.php/olhardeprofessor> 